\title{
A Comparative Study of in hospital Complications among Diabetic Hypertensive Patients and Normal Blood Pressure Diabetic Patients Presented with Acute Myocardial Infarction
}

\author{
BILAL AKHTAR ${ }^{1}$, HAROON ISHAQ ${ }^{2}$, MUHAMMAD TAHSEEN RAZA ${ }^{3}$, MUHAMMAD ISMAIL ${ }^{4}$, IMRAN ELLAHI SOOMRO $^{5}$, \\ RIZWAN KHAN 6 \\ 1,2Senior Registrar National Institute of Cardiovascular Diseases (NICVD) Karachi \\ ${ }^{3}$ Intervention Fellow National Institute of Cardiovascular Diseases (NICVD) Karachi \\ ${ }^{4}$ Assistant Professor Cardiology, National Institute of Cardiovascular Diseases (NICVD), Sukkur \\ ${ }^{5}$ Assistant Professor Cardiology Department of Peoples University of Medical and Health Sciences for Women (PUMHSW) SBA, \\ Nawabshah Sindh \\ ${ }^{6}$ MBBS, FCPS Cardiology, Consultant Interventional Cardiologist National Institute of Cardiovascular Diseases (NICVD), Sehwan \\ Correspondence to: Dr. Bilal Akhtar, E-mail: drbilal2000@hotmail.com, Cell \#: +92-331-2517703
}

\begin{abstract}
Aim: To compare the incidence of in-hospital complications between diabetic normotensive and hypertensive diabetic patients presenting with acute myocardial infarction (MI)

Methodology: This observational cohort study was conducted at National Institute of Cardiovascular Diseases Karachi from May 2019 to April 2020. We examined 220 diabetics with acute Ml were included. 50\% of the patients had high blood pressure and the rest had normal blood pressure. After enrollment in the study, selectees were observed for acute myocardial infarction complications in the hospital.

Results: Most of the baseline characteristics were similar in both groups of patients. However, the hypertensive patients in the diabetes group had diabetes, high heart rate, and high blood pressure at reporting. The complication rates did not differ statistically between the two groups. The rates of complications occurred between diabetes and normotensive hypertension; Atrial fibrillation (AF) $15.5 \%$ vs $12.7 \% \mathrm{p}=0.194$, respectively, ventricular tachycardia (LH) $14.5 \%$ vs $13.6 \%$, AV block type-1 $8.2 \%$ vs $7.3 \% p=0.296$, type 2 AV block $2.7 \%$ vs $1.8 \% p=0.352$, complete heart block $11.8 \%$ vs $10 \% p=0.313$, acute congestive heart failure (CHF) $13.6 \%$ VS\% $9.1 p=0.137$, left ventricular failure (LVF) $19.1 \%$ vs $16.4 \% p=0.259$, cardiogenic shock (CS) $14.5 \%$ vs $10.9 \% p=$ 0.184 , recurrent IM (Re-MI) 14.5\% 10.9\% $\mathrm{p}=0.184$ and mortality $14.5 \%$ vs 12.7 and $\% \mathrm{p}=0.326$, respectively.

Conclusion:It is concluded that diabetic patients with hypertensionhave not elevated risk of complications in the hospital after acute myocardial infarction.

Key words: diabetes, hypertension, hospital complications, acute myocardial infarction
\end{abstract}

\section{INTRODUCTION}

Myocardial infarction is the foremostreason of mortality worldwide. In 2000, it affected hundreds of thousands of people around the world ${ }^{1}$. Its pathogenesis is complicated by many electrical and mechanical complications ${ }^{2}$. These complications are accompanied by the effects of diabetes and hypertension, which are the leading diseases of the modern era. It is valued that the proportion of people with diabetes mellitus will rise from 17 billion to 36 billion amid 2000 and $2030^{3}$. It has affected 6.9 million people in Pakistan and is projected to affect 11.5 million by 2025 . Pakistan's prevalence is estimated at $23 \%$ to $18 \%$ in urban and rural areas ${ }^{4-5}$. It affects about $70 \%$ of diabetics and is twice as common in diabetics. Both of these disorders result in functional and structuralcomplications of the heart and ultimately result in cardiovascular disease and death. Previous studies have clearly shown that diabetes is an independent risk factor for inpatient complications after acute Ml. Hypertension ( $\mathrm{HT})$ is associated with poor prognosis after acute $\mathrm{Ml}^{6-7}$. However, its effects have mainly been studied in nondiabetic patients after acute $\mathrm{Ml}^{8}$. There is little research into the effects of hypertension (HT) on hospital complications in patients with diabetes ${ }^{9}$. Therefore, the goal of this analysis is to compare the incidence of in-hospital complications between diabetic normotensive and hypertensive diabetic patients presenting with acute myocardial infarction (MI)

\section{METHODOLOGY}

This observational cohort study was conducted atNational Institute of Cardiovascular Diseases Karachi from May 2019 to April 2020. The sample size was 220for $10.8 \%$ proportion forcardiogenic shock in hypertensive diabetics and $6.9 \%$ proportionfor normal blood pressure diabetics with $80 \%$ powerand $5 \%$ significance level using the WHO sample size calculation software. It was split between two groups, 110 in each group. The sampling technique used was purposive non probability. The study population consists of non-diabetic hypertensive patients with acute $\mathrm{Ml}$ and diabetic hypertensive with acute $\mathrm{Ml}$ patients. Myocardial infarction (Ml) was diagnosed when 2 of the givenstandards were met: pain suggested of $\mathrm{MI}$ lasted for minimum thirty minutes; secure new changes on electrocardiography; or creatinine kinase (CK-MB isoenzyme) greater than twice the upper limit. Patients with high ST (STEMI) and non-ST (NSTEMI) elevation were enrolled in the study. ST segment elevation myocardial infarction (STEMI) was established after detection of a new ST segment $\geq 1 \mathrm{~mm}$ in two consecutive leads or after detection of a new left bundle branch block on ECG.Patients with chronic use of hyperglycemic antidiabetic drugs (DMs) or fasting blood glucose with evidence of $\geq 126 \mathrm{mg} / \mathrm{dL}(7.0 \mathrm{mmol} / \mathrm{L})$ were definite as diabetes mellitus. Hypertension Medical records include formerlyrecognized chronic blood pressure $\geq 130 / 80 \mathrm{mmHg}$ 
or using antihypertensive drugs were labeled as hypertensive. The patients age ranges between25 to70 years of age irrespective of the gender. Pastvalvular heart disease, congestive heart failure, all types of cardiomyopathies, congenital heart disease, ventricular tachycardia, primary or secondary pulmonary arterial hypertension, advanced AV block, atrial fibrillation, left bundle branch block and permanent pacemakers fitted patients were not included as these conditions augment the current situation resulting in misdiagnosis. Chronic renal failure (CRF) patients who underwent coronary artery bypass graft (CABG) surgery and have myocardial infarction history were also not included as among themthe complication rate of $\mathrm{Ml}$ is very high and test results obtained may be false.

After approval by the hospital ethics committee, patients meeting the above inclusion criteria were included. With the patient's written consent, the patient's history will be reviewed and clinically analyzed. CK-MB, fasting blood sugar (FBS), and hemoglobin $(\mathrm{Hb})$ were obtained in the hospital lab. Mean Blood sugar levels are derived from five levels of average blood sugar. Treatment variables (primary $\mathrm{PCl}$ or thrombolysis) were taken into account. Patients remained in the hospital for five days until they were needed. It controls hospital complications such as electrical complications (advanced AV block, VF, VT, and AV), mechanical complications (CS, LVF, CHF), recurrent heart attacks, and death in hospital. Cardiac and ECG monitors were used to control electrical complications and recurrent MI. Mechanical complications were determined on the basis of a clinical examination and echocardiography. When patients developed new chest pain, CK-MB and ECG were performed to detect therecurrent Ml. All this data is saved in Proforma. Confounding variables listed in the exclusion criteria were monitored. Study bias was controlled by strict inclusion criteria for patient selection, measurable operative definitions to diagnose complications, and the same ECG and echocardiography equipment for all patients.

The statistical survey was conducted using version 16 for the Social Sciences (SPSS). Numerical variables are presented as mean \pm SD. Categorical variables are presented as percentage and frequency. The two groups comparison were made with the student's t-test for numerical variables and for categorical variables chi-square test was applied. $\mathrm{P}$ value was considered significant as $\leq$ 0.05 . The results are presented in tabular form.

\section{RESULTS}

Of the 220 diabetic patients with acute MI, 210 had hypertension and 210 had normal blood pressure. Patient characteristics and coronary parameters are presented in Table 1.

Maximum of the baseline features were statistically comparable in both groups. Though, the hypertensive diabetic patients had a long history of high blood pressure, diabetes and high heart rate compared to the diabetics with normal blood pressure.

Table-1: The Patients demographic features are given

\begin{tabular}{|l|l|l|l|}
\hline Baseline & Diabetic & Diabetic & \multirow{2}{*}{ P-value } \\
\hline Characteristics of Patients & Hypertensive Group $\mathrm{n}=110$ & Normotensive Group $\mathrm{n}=110$ \\
\hline Female (\%) & $49(44.45)$ & $43(39.1)$ & 0.158 \\
\hline Male (\%) & $61(55.5)$ & $67(60.9)$ & 0.158 \\
\hline Mean Age & $54.11 \pm 9.03$ & $54.30 \pm 9.04$ & 0.3 \\
\hline Duration of DM (years) & $6.26 \pm 3.82$ & $4.01 \pm 2.02$ & \\
\hline Duration of HT (Years) & $3.47 \pm 3.04$ & & \\
\hline STEMI (\%) & $75(68.2)$ & $73(66.4)$ & \\
\hline NSTEMl (\%) & $35(31.8)$ & $37(33.6)$ & 0 \\
\hline Anterior Ml on ECG (\%) & $32(29.1)$ & $28(25.5)$ & 0.32 \\
\hline Heart Rate (Beats/min) & $84.05 \pm 17.43$ & $79.34 \pm 15.19$ & 0.32 \\
\hline Systolic Blood Pressure (mmHg) & $145.05 \pm 25.23$ & $125.52 \pm 15.49$ & 0 \\
\hline Diastolic Blood Pressure (mmHg) & $8005 \pm 17.24$ & $69.28 \pm 15.36$ & 0.002 \\
\hline Mean blood glucose(mg/dl) & $131.22 \pm 35.35$ & $134.07 \pm 35.01$ & 0 \\
\hline Hemoglobin level(g/dl) & $10.55 \pm 2.17$ & $10.64 \pm 1.57$ & 0 \\
\hline Symptoms to Thrombolytic time(hours) & $2.04 \pm 1.02$ & $2.42 \pm 1.09$ & 0.797 \\
\hline Thrombolytic Therapy (\%) & $64(58.2)$ & $54(49.1)$ & 0.937 \\
\hline Primary PCl (\%) & $2(1.8)$ & $2(1.8)$ & 0.059 \\
\hline
\end{tabular}

Table 2: The rates of complications between both groups were statistically insignificant

\begin{tabular}{|l|l|l|l|}
\hline Complications of MI & Diabetic Hypertensive Group & Diabetic Normotensive Group & P-value \\
\hline Atrial Fibrillation (\%) & $17(15.5)$ & $14(12.7)$ & 0.194 \\
\hline Ventricular Tachycardia (\%) & $16(14.5)$ & $15(13.6)$ & 0.34 \\
\hline Ventricular Fibrillation (\%) & $6(5.5)$ & $4(3.6)$ & 0.395 \\
\hline Type 1 Second degree AV block (\%) & $9(8.2)$ & $8(7.3)$ & 0.286 \\
\hline Type 2 Second degree AV block (\%) & $3(2.7)$ & $2(1.8)$ & 0.352 \\
\hline Complete heart block (\%) & $13(11.8)$ & $11(10.0)$ & 0.313 \\
\hline Acute Left Ventricular Failure (\%) & $21(19.1)$ & $18(16.4)$ & 0.259 \\
\hline Congestive Heart Failure (\%) & $10(9.1)$ & 0.137 \\
\hline Cardiogenic Shock (\%) & $15(13.6)$ & $12(10.9)$ & 0.04 \\
\hline Recurrent MI (\%) & $16(14.5)$ & $12(10.9)$ & 0.184 \\
\hline In-hospital death (\%) & $16(14.5)$ & $14(12.7)$ & 0.326 \\
\hline
\end{tabular}


The rates of complications occurred between diabetes and normotensive hypertension; Atrial fibrillation (AF) $15.5 \%$ vs $12.7 \% \mathrm{p}=0.194$, respectively, ventricular tachycardia (LH) $14.5 \%$ vs $13.6 \%$, AV block type-1 $8.2 \%$ vs $7.3 \% p=0.296$, type 2 AV block $2.7 \%$ vs $1.8 \% p=0.352$, complete heart block $11.8 \%$ vs $10 \% p=0.313$, acute congestive heart failure (CHF) $13.6 \%$ VS\% $9.1 p=0.137$, left ventricular failure (LVF) $19.1 \%$ vs $16.4 \% p=0.259$ cardiogenic shock (CS) $14.5 \%$ vs $10.9 \% \mathrm{p}=0.184$, recurrent IM (Re-MI) 14.5\% 10.9\% $\mathrm{p}=0.184$ and mortality $14.5 \%$ vs 12.7 and $\% p=0.326$, respectively.

There was no variance in the complication rates amid the two groups according to the sex of the patients.

\section{DISCUSSION}

This study did not show an additional risk of hypertension in hospital complications following acute $\mathrm{Ml}$ in patients with diabetes $^{9-10}$. It showed no interaction between hypertension and diabetes mellitus in terms of complications in acute $\mathrm{MI}^{11}$. In line with published international data. Jonas et al. Recently, 4,317 diabetic patients with or without hypertension have been studied ${ }^{12}$. In terms of hospital complications, they do not pose an additional risk of acute hypertension. However, yearly, the deaths and congestive heart failure were higher in diabetic hypertensive patients than in diabetic patients with normal blood pressure. It was a retrospective study and patient data was taken from the registries of CCU in Israel ${ }^{13-14}$. Our study, on the other hand, was a potential study, and the patients were followed up with hospitalized complications. Second, both groups had higher rates of hospitalization-related complications compared to the patients in that study ${ }^{15}$. For example, the cardiogenic shock incidence in Israel study was $10.6 \%$ and $6.8 \%$ in people with normal blood pressure and diabetic hypertension. In our study, it is $14 \%$ and $10.4 \%$, respectively, for diabetic patients with hypertension and for diabetic patients with normal blood pressure. The higher complication rate of this study and its causes can be explained $^{16}$. First, poor control of diabetes and hypertension in our patients, second, due to late clinical treatment due to ignorance of $\mathrm{Ml}$ and poor logistical support, third, primary $\mathrm{PCl}$ in $\mathrm{Ml}$ patients was considered late as primary $\mathrm{PCl}$ has higher efficacy than pharmacological improvement, and fourth higher Mortality among Asians ${ }^{17-18}$.

Most of the other studies comparing the outcomes of hospitalization in patients with or without hypertension in diabetics and adverse clinical events in the hospital, especially heart failure, were more common in patients with diabetes and hypertension than only with hypertension $(40.3 \%$ vs. $18.1 \%) . P=0.01)$.

Most of the research work in the past has looked at the long-term effects of high blood pressure on acute MI. History of hypertension has been revealed to rise the longterm risk of chronic heart failure (HF) and other adverse cardiac events, even when re-perfused by primary $\mathrm{PCI}$ or thrombolytic therapy. However, these studies did not look for hospital complications ${ }^{19-20}$.

Considerable clinical and experimental evidence shows that hypertension is very significant in the diabetic heart disease pathogenesis ${ }^{21-22}$. CAD is verycommunalamong patients with diabetes and hypertension as compared to theindividuals with diabetes mellitus or hypertension only, and the progress of atherosclerosis is accelerated with greater fragmentation of atherosclerotic plaques and a low coronary perfusion reserve in diabetic patients along with hypertension. Patients with hypertension and diabetes have abnormal systolic and diastolic functions of the ventricles with congestive heart failure and left ventricular hypertrophy, counterparts those with diabetes or hypertension ${ }^{23}$.

Contrary to expectations, the risk of complications in hospitals after acute MI was similar in patients with diabetes mellitus than with or deprived of hypertension. High blood pressure quickens heart disease complications among diabetic. Long-term follow-up is possible to see the effect of hypertension on the complications of $\mathrm{Ml}$. Otherwise, hypertension history will not upsurgedeath rate if it is controlled well. In this analysis, patients with hypertension had relatively controlled blood pressure. Initially, mean blood pressure was $149 / 84 \mathrm{mmHg}$ in diabetic hypertensive patients and $130 / 72 \mathrm{mmHg}$ in diabetic normotensive patients, suggesting good hypertension control. It also supposed that lower blood pressure in few hypertensive individuals after a heart attack to better control the high blood pressure ${ }^{24}$. If so, proper BP monitoring can eradicate the additional jeopardy of hypertension in diabetes, and thus have betterrecovery of diabetics with IHD.Tenenbaum et al. They have newly shown that hypertension is an independent predictor of amplified mortality in diabetics managed with diet control, but not in chronic ischemic heart disease, signifying the benefits of primary control of blood pressure in these inhabitants. Support for intensive and hypertensive treatment of patients with DM was also seen in Study of Optimal Treatment of Hypertension ${ }^{25}$. In this analysis, diabetic patients who are hypertensive achieved the greatest benefit from lowering blood pressure, with a $51 \%$ decrease in main cardiovascular complications in the 80$\mathrm{mmHg}$ target group compared to the $90-\mathrm{mmHg}$ group. Blood pressure should be monitored above the recommended values suggested by the guidelines ${ }^{26}$. The topic was recently raised in the Atlantic on April 29, 2018 and was presented on the ACCORD tour at the 59th annual meeting of the University of Cardiology. The researchers randomly assigned to systolic blood pressure 4,733 participants with high blood pressure below 120 $\mathrm{mmHg}$ (intensive group) or $140 \mathrm{mmHg}$ (standard group) ${ }^{25-}$ 26. After a median follow-up of about five years, the researchers found no significant difference in the combined endpoint between the intensive care unit and the standard care unit, with no cardiovascular death. Several studies have shown gender differences in the effects of diabetes on heart attack outcomes in women with a worse prognosis. In the current analysis of Ml patients, the risk of hospital complications was similar in men and women in the diabetic and hypertensive diabetic groups.

\section{CONCLUSION}

It is concluded that diabetic patients with hypertension have not elevated risk of complications in the hospital after acute myocardial infarction. 


\section{REFERENCES}

1. Her AY, Choi BG, Rha SW, Kim YH, Choi CU, Jeong $\mathrm{MH}$. The impact of angiotensin-converting-enzyme inhibitors versus angiotensin receptor blockers on 3year clinical outcomes in patients with acute myocardial infarction without hypertension. Plos one. 2020 Nov 30;15(11):e0242314.

2. Hsu PC, Lee WH, Chiu CA, Chen YC, Chang CT, Tsai WC, Chu CY, Lin TH, Voon WC, Lai WT, Sheu $\mathrm{SH}$. Usefulness of ankle-brachial index calculated using diastolic blood pressure for prediction of mortality in patients with acute myocardial infarction. The Journal of Clinical Hypertension. 2020 Nov;22(11):2044-50.

3. Ma X, Sun Y, Cheng Y, Shen H, Gao F, Qi J, Yang L, Wang Z, Shi D, Liu Y, Liu X. Prognostic impact of the atherogenic index of plasma in type 2 diabetes mellitus patients with acute coronary syndrome undergoing percutaneous coronary intervention. Lipids in Health and Disease. 2020 Dec;19(1):1-3.

4. Badran HM, Fatah AA, Soltan G. Platelet/lymphocyte ratio for prediction of no-reflow phenomenon in STelevation myocardial infarction managed with primary percutaneous coronary intervention. Journal of Clinical and Translational Research. 2020 Jul 16;6(1):20.

5. Ravikanth $R$. Relevance of carotid intima-media thickness and plaque morphology in the risk assessment of patients with acute ischemic cerebral infarcts: A case-control study of large series from a single center. Journal of medical ultrasound. 2020 Jan;28(1):29.

6. Li X, Kong T, Yao Y, Chen J, Sun K, Zhang S, Hui R, Fan $X$. Prevalence and factors associated with fast resting heart rate in hypertensive and normotensive patients. Clinical and Experimental Hypertension. 2020 Jan 2;42(1):8-15

7. Vulin A, Todic VD, Stefanovic M, Popov T, Poljak JP, Ljubotina A, Popov I, Petrovic M. PROGNOSTIC SIGNIFICANS OF EARLIER HYPERTENSION, NORMAL AND HIGH ADMISSION SYSTOLIC BLOOD PRESSURE OF PATIENTS WITH MYOCARDIAL INFARCTION WITH AND WITHOUT ST ELEVATION. Journal of Hypertension. 2021 Apr 1;39:e155.

8. Hu C, Han H, Sun Y, Cheng Y, Liu Y, Liu J, Gao A, Zhou Y, Zhang J, Zhao Y. Small Dense Low Density Lipoprotein and Cardiovascular Events in Patients With Acute Coronary Syndrome Undergoing Percutaneous Coronary Intervention: A Cohort Study From China.

9. Siraj J, Ali U, Ahmed T, Ali H. Frequency of in hospital mortality in patients with high neutrophil/lymphocyte ratio presenting with st elevation myocardial infarction. Pakistan Heart Journal. 2020 Apr 27;53(1).

10. Ma X, Dong L, Shao Q, Cheng Y, Lv S, Sun Y, Shen $\mathrm{H}$, Wang Z, Zhou Y, Liu X. Triglyceride glucose index for predicting cardiovascular outcomes after percutaneous coronary intervention in patients with type 2 diabetes mellitus and acute coronary syndrome. Cardiovascular diabetology. 2020 $\operatorname{Dec} ; 19(1): 1-4$.
11. Mohamed A, Alramlawy S, El-Hadidy S, Affify MI, Radwan W. Subtle Right Ventricular Affection in Patients with Acute Myocardial Infarction, Echocardiographic Assessment. Open Access Macedonian Journal of Medical Sciences. 2020 Nov 6;8(B):1212-8.

12. Wang L, Wu D, Ji X. Letter by Wang et al Regarding Article,"Hypertensive Response to Ischemic Stroke in the Normotensive Wistar Rat: Mechanisms and Therapeutic Relevance”. Stroke. 2020 Feb;51(2):e32-

13. Haji GF, Mulla NK, Mahmood FS, Abdulrazzaq HA Ali A, Mohammed K. Prevalence, risk factors and short term outcomes of acute myocardial infarction in Baghdad teaching hospital, 2019.

14. Schmitz T, Thilo C, Linseisen J, Heier M, Peters A, Kuch B, Meisinger C. Low serum calcium is associated with higher long-term mortality in myocardial infarction patients from a populationbased registry. Scientific reports. 2021 Jan 28;11(1):1-8.

15. Tocci G, Presta V, Ferri C, Redon J, Volpe M. Blood pressure targets achievement according to 2018 $\mathrm{ESC} / \mathrm{ESH}$ guidelines in three European excellence centers for hypertension. High Blood Pressure \& Cardiovascular Prevention. 2020 Feb;27(1):51-9.

16. Zhang $\mathrm{C}$, Bangming CA, Huang X, Jian GU, Ming XI, Xiangjun YA, Hongxia LI. Association between Serum Calcium and First Incident Acute Myocardial Infarction: A Cross-Sectional Study. Iranian journal of public health. $2020 \mathrm{Jul} ; 49(7): 1278$.

17. Mrsic D, Smajlovic J, Loncar D, Avdic S, Avdagic M, Smajic E, Bajric M, Jahic A. Risk Factors in Patients with Non-ST Segment Elevation Myocardial Infarction. Materia Socio-medica. 2020 Sep;32(3):224.

18. Wang $Y$, Newsome GS. The Rise of ST-Elevation Myocardial Infarction in Women of Northeast China. Gerontology and Geriatric Medicine. 2021 Feb;7:2333721421992250.

19. Iqbal F, Soliman A, De Sanctis V, Mushtaq K, Nair AP, Al Masalamani MA, Sasi S, Ali EA, Hassan OA, Nashwan AJ, Fahad J. Prevalence, clinical manifestations, and biochemical data of hypertensive versus normotensive symptomatic patients with COVID-19: a comparative study. Acta Bio Medica: AteneiParmensis. 2020;91(4).

20. Sezer H, Yazici D, Copur S, Dagel T, Deyneli O, Kanbay $M$. The relationship between glycemic variability and blood pressure variability in normoglycemic normotensive individuals. Blood Pressure Monitoring. 2021 Apr 1;26(2):102-7.

21. Pennefather C, Esterhuizen T, Doubell A, Decloedt $\mathrm{EH}$. The 12-month period prevalence and cardiac manifestations of HIV in patients with acute coronary syndrome at a tertiary hospital in Cape Town, South Africa: a retrospective cross-sectional study.

22. Azevedo RB, Botelho BG, Hollanda JV, Ferreira LV, Andrade LZ, Oei SS, Mello TD, Muxfeldt ES. Practical Approach to Acute Coronary Syndrome in Patients with COVID-19. International Journal of Cardiovascular Sciences. 2021(AHEAD). 
23. Shaikh ZA, Shamim J, Bhatti AK, Soomro S, Kiran Z, Matloob SA. Association of Diabetes and Hypertension as risk factors with Ischemic Heart Disease among patients visiting a Public Sector Tertiary Care Hospital of Karachi, Pakistan. Pakistan Journal of Public Health. 2020;10(4):215-9.

24. Gheblawi M, Wang K, Viveiros A, Nguyen Q, Zhong JC, Turner AJ, Raizada MK, Grant MB, Oudit GY. Angiotensin-converting enzyme 2: SARS-CoV-2 receptor and regulator of the renin-angiotensin system: celebrating the 20th anniversary of the discovery of ACE2. Circulation research. 2020 May 8;126(10):1456-74.
25. Ibrahim IM, Abdel-Kareem AR, Mahfouz RA, Shehata IE. The Association Between Morning Blood Pressure Surge and Cardiovascular Disease in Normotensive Type 2 Diabetic Patients: Observational Analytical Study in the Form of a Cross-Sectional Study. SN Comprehensive Clinical Medicine. 2021 Apr;3(4):95563.

26. Galag SC, Rajalakshmi R, Desai N, Basavanagowdappa $\mathrm{H}$. The effect of deep breathing test on heart rate variability in obese and non-obese patients with myocardial infarction. Biomedicine. 2021 Apr 3;41(1):93-8. 